
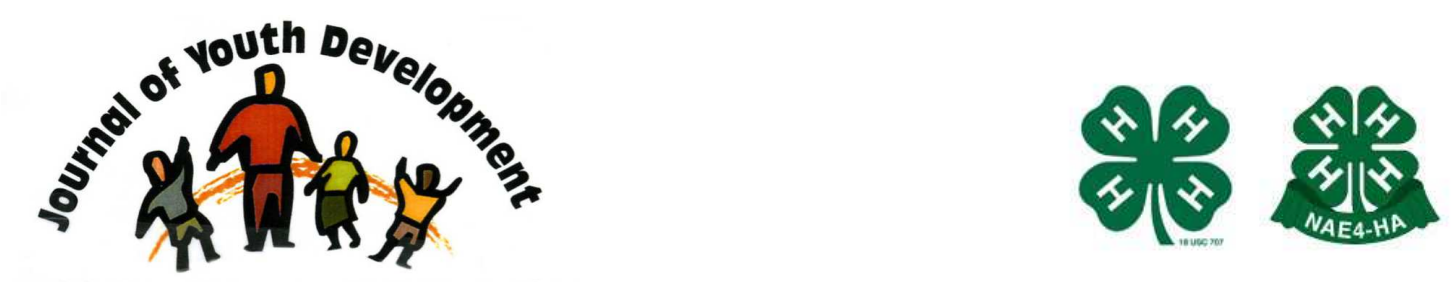

Bridging Research \& Practice

\title{
A Process and Outcome Evaluation of Police Working with Youth Programs
}

Stephen A. Anderson

University of Connecticut

Stephen.Anderson@uconn.edu

Ronald M. Sabatelli

University of Connecticut

Ronald.Sabatelli@uconn.edu

Jennifer Trachtenberg

University of Connecticut

Jennifer.VanBuren@uconn.edu 


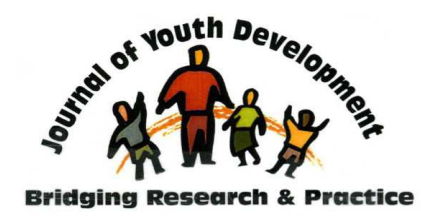

Volume 3, Number 2, Fall 2008

\section{JOURNAL OF YOUTH DEVELOPMENT \\ bridging research and practice}

Article 080302FA002

\title{
A Process and Outcome Evaluation of Police Working with Youth Programs
}

\author{
Stephen A. Anderson, Ronald M. Sabatelli and Jennifer Trachtenberg \\ University of Connecticut
}

\begin{abstract}
A process and outcome evaluation of 10 Police Working with Youth Programs was conducted. Process results indicated that the core components of the programs were consistent with those identified in previous literature as characteristic of quality youth development programs. Outcome results indicated that youth participants reported significantly improved attitudes toward police and social support received from significant, non-familial adults. Two subgroups of youth, most notably minority youth and younger participants in lower grade levels, reported positive changes in their capacity to resist peer pressures. Minority youth reported positive changes in their sense of mastery over stressful life situations. Relationships between core program components and youth outcomes also were examined. Implications of the findings and future process and outcome evaluations of youth programs are discussed.
\end{abstract}

\section{Introduction}

Research has suggested that community youth development programs produce positive youth outcomes. Such programs seek to promote youth development, as opposed to intervening in specific problems, by fostering intellectual, social and emotional competencies. These competencies serve as protective factors, and lessen the likelihood that youth will engage in harmful or destructive behaviors (Roth \& Brooks-Gunn, 2003). Community youth development programs have been shown to improve youths' academic success (e.g., grades, motivation, and commitment to schooling), vocational achievement, and social development (e.g., positive identity, personal efficacy, self-regulation, resistance skills, problem-solving skills and quality of adult and peer relationships) (Catalano, Berglund, Ryan, Lonczak, \& Hawkins, 2002; Eccles, \& Gootman, 2002; Roth, Brooks-Gunn, Murray, \& Foster, 1998). 
However, there are a wide variety of community programs that fall under the rubric of "youth development programming." Examples are community youth drop-in centers (Hirsch, 2005; McLaughlin, Irby, \& Langman, 2001), after school mentoring programs (Rhodes, 2002), youth leadership training (Boyd, 2001), and community civic involvement projects (Hamilton \& Hamilton, 2004). It is unclear whether or not these different types of youth development programs can be equally effective.

\section{Police Working with Youth Programs.}

Police working with youth in non-enforcement roles is one type of community youth development program that has received even less attention. Based in part upon a community policing model, which has become common in law enforcement, these programs bring police together with local youth in the community in Police Athletic Leagues, Police Explorer Scouts, and other activities such as fairs or summer camps (Greene, 2000; Roth et al., 2000). However, there are relatively few studies that examined the effectiveness of engaging youth and police in non-enforcement roles to promote youth development.

Changes in police and youth attitudes toward each other following participation in a 6-week basketball program offered by a Police Athletic League was examined in one study. Results indicated that police officers reported significantly improved attitudes toward minority youth on their teams and toward minority youth in general. However, youth reported improved attitudes only towards team members (police officers and peers), but not toward police on the whole (Rabois \& Haaga, 2003). In another study, police worked with economically disadvantaged, inner-city youth as role models and instructors in a variety of activities such as community clean-up projects, recreational activities, and tours of local businesses. Police also gave talks about themselves and their work. Observations, focus group interviews, and surveys of parents and participating staff indicated that the program was successful in instilling a sense of responsibility in youth, improving some youth and parents' attitudes toward police, and improving participating officers' attitudes toward youth. However, as the researchers noted, the short-term nature of the program (8 weeks) and lack of follow-up did not allow for conclusions about long-term impact (Thurman, Giacomazzi, \& Bogen, 1993).

One of the most comprehensive evaluations of police working with youth programs was an evaluation conducted with 17 programs, in both urban and suburban communities, in the State of Connecticut (Anderson, Sabatelli, \& Trachtenberg, 2007). A variety of police working with youth programs including, Police Academies, athletic leagues, adventure activities programs, and Police Explorers Scouts programs were studied. It was found that a subgroup of youth who entered these one-year programs at a lower level of psychosocial functioning showed significantly more positive changes than a comparison group of youth who began the program with a higher level of overall psychosocial adjustment. Despite these significant findings, the study did not address whether or not youth changed their attitudes toward police (an important overall goal of such programs) or what specific program components accounted for the significant changes reported by youth participants. In fact, this latter issue, regarding what specifically accounts for positive changes following completion of a community youth development program, remains largely unanswered.

\section{Effective Youth Programs.}

Little empirical evidence is available to indicate what program components or combination of components within effective youth programs are responsible for positive outcomes (Eccles, 2005; Eccles \& Gootman, 2002; Kahne et al., 2001; Lopez \& McKnight, 2002; Scott-Little, Hamann, \& Jurs, 2002). Process researchers have been adamant in pointing out that "black 
box" approaches that focus on recording positive changes in participants while ignoring what actually happens in the program are inadequate. Further, we cannot assume that a program operates exactly as it was originally planned. Rather, what are needed are research designs that study the processes actually operating within programs and how these processes aft the results that are achieved (Dehar, Casswell, \& Duignan, 1993; McLaughlin, 1987; Wholey, Hatry, \& Newcomer, 1994).

Catalano et al. (2002) reported that none of the studies included in their comprehensive review of youth development program evaluations included information about the program, the implementation process, or the relationship between the implementation process and outcomes. Larson (2000) in his analysis of the field of youth development concluded that, like other fields, outcome evaluations have been needed to justify funding for youth activities even though we are not yet sure what might be the independent and dependent variables for such evaluative research. He proposed that a first step should be descriptive and process research that helps to conceptualize the essential elements of developmental change.

Although such descriptive and process research has been limited to date, a number of researchers and theorists have proposed criteria for effective youth programs. Often these formulations have supplemented the limited direct empirical evidence on community youth development programs with other sources of information such as theories of adolescent development (Eccles \& Gootman, 2002), research on adolescents' mental health and adjustment (Durlak \& Wells, 1997, 1998), prevention programs targeting risk and protective factors (Catalano et al., 2002), and school-based after-school programs (Kahne et al., 2001; Posner \& Vandell, 1994).

Despite differences in the criteria proposed by these authors for assessing quality youth development programs, there is near universal agreement on several of the factors deemed to be essential. These include:

- safety,

- supportive relationships,

- challenging activities, and

- meaningful involvement

(Connell, Gambone, \& Smith, 2000; Eccles \& Gootman, 2002; Gambone, Cao Yu, Lewis-Charp, Sipe, \& Lacoe, 2004; Walker, Marczak, Blyth, \& Borden, 2005; Yohalem, Pittman, \& WilsonAhlstrom, 2004).

\section{Safe and Secure Environment.}

Numerous authors have emphasized that positive development must begin in an environment that is both physically and psychologically safe and secure (c.f., Gambone et al., 2004; Vandell, Shumow, \& Posner, 2005). For instance, Eccles and Gootman (2002) noted that positive settings must be free from violence and unsafe health conditions because of their direct impact on physical health and survival. Furthermore, research on children and adolescents has consistently identified a safe and trusting environment as essential for healthy development and adjustment (Bowlby, 1988; Erikson, 1968; Rohner \& Britner, 2002).

\section{Supportive Relationships.}

Several reviews of youth program evaluations have concluded that supportive relationships with staff and other non-familial adults are one of the most frequently identified characteristics of effective youth programs (Catalano et al., 2002; Eccles \& Gootman, 2002; Roth et al, 1998). 
More recent studies not included in earlier reviews have supported these earlier conclusions. Youth-staff relationships have been found to be a key determinant of both retention and success in youth programs (Noam \& Fiore, 2004; Rhodes, 2004).

Offering challenging and stimulating activities that lead to the development of life skills is another frequently identified characteristic of effective youth programs (Catalano et al., 2002, Eccles \& Gootman, 2002; Eccles, Stone, \& Hunt, 2003; Roth et al, 1998; Walker et al., 2005). Organized activities offer youth opportunities to acquire social, physical, and intellectual skills that may be useful in a wide variety of settings including school. Furthermore, they provide opportunities to contribute to the well-being of the community and develop a sense of agency as a member of the community. Belonging to socially recognized and valued groups allows one to establish supportive networks with peers and adults, and experience and deal with challenges. Catalano et al. (2002) concluded, on the basis of the results they reviewed, that $75 \%$ of effective programs targeted increased opportunities for youth participation in positive social activities, and recognition and reinforcement for that participation. Larson (2000) has argued that a core component of positive development is initiative, which only develops when concerted effort is combined with experiences that are complex and challenging. He found that structured voluntary activities such as sports, arts, and participation in organizations were the contexts where these elements of initiative were most likely to co-occur.

Meaningful involvement, the fourth major component of effective youth programs, has been referred to with a variety of terms such as opportunities to belong, support for mattering, acceptance, and inclusion (Eccles \& Gootman, 2002). Some out-of-school youth programs, especially those serving low-income youth in dangerous neighborhoods, have been described as providing a "family-like quality" (Halpern, Barker, \& Mollard, 2000). In such a setting, youth know one another well, accept each others' quirks, tease each other but not too harshly, and describe each other as friends. However, meaningful involvement entails more than a sense of belonging. It also includes opportunities for active participation in decision-making, responsibility, and leadership. Youth are encouraged to have an active voice in decision-making within the organizations that influence their lives (O'Donoghue, Kirshner, \& McLaughlin, 2002). Finally, meaningful involvement includes active participation in one's community. At this level, it involves planning and involvement in public action, as in the case of community service activities, and access to political, and economic spheres (O'Donoghue et al., 2002; Tolman \& Pittman, 2001).

\section{Program Description}

The primary objective of the present study was to conduct a process evaluation of Police working with Youth Programs to identify the core elements of the program and to assess the degree to which these core elements were consistent with established youth development programming principles. A second objective was to determine the extent to which youth changed their perceptions of police in their communities following completion of the program. Our third objective was to assess the extent to which youth participants reported changes on several youth development outcomes included in the study. Finally, we were interested in examining whether the core program components implemented within the Police programs were associated with positive youth outcomes.

Police Working with Youth in Non-enforcement Roles is a program funded by the State of Connecticut through the Office of Policy and Management. It provides funds for local communities to increase or enhance positive police interactions with youth outside of the 
traditional enforcement role. Programs are generally funded for a one-year period. A total of 10 community programs were funded during the evaluation period, September 2004 and August 2005. Three of the 10 programs were in major cities, and the rest were in suburban towns and communities. Communities offered different types of programs tailored specifically to the available resources in that community. However, all included regular interaction with police officers in a variety of roles and activities. Three communities offered Police Academies. Police academies generally consisted of law enforcement classes and seminars offered on a regular basis. They included lectures, role-plays and demonstrations, military drills similar to what recruits at the adult Police Academy experience and field trips to police facilities. Lectures covered such topics as bicycle safety, gun safety, fire safety, and cultural diversity. Two programs offered after-school recreational programs that generally included athletic teams and other adventure activities.

One program offered a Police Explorers Scouts program. Explorer programs involved young men and women in police operations designed to interest them in law enforcement. Youth were expected to develop leadership skills and became familiar with basic law enforcement skills and procedures such as traffic control, arrest and search, bomb threat response, crime prevention, crime scene search, and white collar crime. Finally, police in four communities engaged youth in the development of youth councils. Police worked closely with youth in a variety of roles including planning sessions for field trips and community service projects.

Although the programs differed in terms of their program content, they all shared a number of common characteristics. The programs were open to any interested youth. All programs were expected to offer open, instrumental, and supportive relationships between youth and police. In addition, all programs were expected to offer a safe environment, challenging and stimulating activities, opportunities for youth to be involved in leadership and decision-making roles, and community or civic involvement. As was noted earlier, these characteristics have all been found to be associated with high quality youth development programs (Eccles \& Gootman, 2002; Gambone \& Arbreton, 1997; Roth et al., 1998; Yohalem et al., 2004).

\section{Evaluation Design}

Youth leaders in each program were chosen by program staff and then trained as observerreporters by the evaluation team to complete Project Activity Reports after each program meeting or activity. The Project Activity Reports documented attendance, the type of activity (planning meeting, field trip, training session, etc), purpose of the meeting, and a qualitative description of the activities that took place between police and youth. All sheets were signed by the youth observer and a staff member to document their agreement on the content provided.

The evaluation design also involved administering pre-test and post-test surveys to youth who were engaged in youth development activities in the participating communities. Each program was asked to include all youth who had participated in their program in the outcome portion of the evaluation.

The evaluation sought to answer the following questions:

1. Based upon the reports collected by youth observers, what kinds of activities and program components are most frequently offered in Police Working with Youth Programs? Are these activities and program components consistent with those deemed to be essential for successful youth development programs? 
2. Do youth who participate in Police Working with Youth programs report improved attitudes toward police following completion of the programs?

3. Do youth who participate in Police Working with Youth programs report improved developmental outcomes following completion of the programs?

4. Are program implementation processes (program components) associated with positive youth outcomes?

\section{Outcomes Included in the Evaluation}

It was hypothesized that youth who participated in these programs would likely show changes in three general categories of outcomes (Sabatelli, Anderson, \& LaMotte, 2005). These included youth personal adjustment, social competencies, and positive adult-youth connections. The specific outcomes included in the evaluation are described below according to each of these outcome categories.

Personal adjustment. It was hypothesized that Police Working with Youth programs would have a positive influence on participants' self-efficacy. Self-efficacy is defined as, the belief in one's capacities to organize and execute the sources of action required to manage prospective situations (Bandura, 1997). It is a context-specific assessment of competence to perform a specific task or domain. This means that accurate assessments of self-efficacy must be based upon specific skills or skill sets. For this evaluation, one skill set that had been found in an earlier evaluation of Police Working with Youth programs to show positive change was included. This was self-regulatory efficacy, which was defined as the ability to resist negative peer pressures.

It was further hypothesized that youth working with police also would develop a greater sense of mastery or personal control over their environment. It was thought that focus on developing leadership, communication, and decision-making skills in the context of recreational, adventure, or other structured police training activities would naturally translate into an enhanced sense of personal control, or the capacity to manage the day-to-day stresses and strains encountered by youth. It also was anticipated that exposure to the skills emphasized in Police Working with Youth programs would enhance youth participants' feelings of self-adequacy and positive selfconcept.

Social competencies. A social competency thought to be affected by Police Working with Youth programs was one's sense of social responsibility. Social responsibility involves a commitment to the community and the well-being of others. The emphasis in Police programs on service to others was evident in the community service projects that youth participated in and the skills training youth received in Police Explorer and Police Academy programs.

Adult-youth connections. The nature of Police Working with Youth programs is such that youth who become involved spend a good deal of time interacting with adults in a variety of experiences. It was hypothesized that, as a result, youth in these programs would develop supportive relationships with adults (staff) and perceive these adults as resources for dealing with social and emotional challenges.

\section{Sample: Characteristics of Youth Participants}

The participants in this evaluation were youth who completed a year-long Police Working with Youth program funded by the State of Connecticut, Office of Policy and Management between September 2004 and August 2005. Ten programs were evaluated and a total of 141 participating youth completed the pre-test and end-of-year assessment. 
The sample was comprised of 84 males (59.6\%) and 57 (40.4\%) females. Their grade levels in school ranged from middle school through high school, with ninth grade being the average. Ninety-nine percent $(n=138)$ of the sample fell within grades seven through twelve. An additional $1.4 \%$ of the participants did not report their grade in school. The average age of participants was 14 years. Thirty percent $(n=42)$ of the youth reported an A grade point average in school and another $49 \%(n=69)$ reported a $B$ grade point average. Nineteen percent $(n=26)$ reported a $C$ average and $2 \%(n=3)$ reported a $D$ average in school. No participants reported an $\mathrm{F}$ grade point average. Only one participant did not report her GPA.

This sample was mainly Caucasian (56\%). Among the remaining participants, $14 \%$ were African American, 15\% were Hispanic/Latino, 3\% were Asian, and 4\% were American Indian. These statistics closely approximate population data on the State of Connecticut. Another 7\% reported "other." In addition to these demographics, youth were asked to report their family status, or the caregivers living with them in the home. The majority $(50 \%$ reported living with both their mother and father. About $26 \%$ reported living with their mother only, and another $13 \%$ reported living with their mother and stepfather. A little over $2 \%$ reported living with their father and stepmother. The remaining youth lived with other relatives (7\%), foster parents $(1 \%)$, or non-relatives (1.5\%). One participant did not answer this question.

\section{Measures}

Self-regulatory efficacy. The 9-item Self-Regulatory Efficacy scale (sample items: "How well can you resist peer pressure to drink beer, wine, or liquor?" and "how well can you resist peer pressure to do things in school that can get you into trouble?") was derived from the Multidimensional Scales of Perceived Self-Efficacy (Bandura, 2001). The scale has been used extensively in research and has well-established reliability and validity. The scale was previously shown to have alpha reliabilities that ranged from .79 to .85 (Bandura, in press; Miller, Coombs, \& Fuqua, 1999). Average alpha reliability (pre-test and post-test combined) in the present study was .88.

Mastery. Sense of mastery has been studied extensively in past research and found to be a strong predictor of one's ability to cope with stressful situations. The sense of mastery scale was developed by Pearlin and Schooler (1978) and is one of the most widely used measures of personal coping. It assesses one's sense of personal control over, or capacity to manage, stressful situations and events. In the present study, the scale averaged an alpha reliability of .75 over two administrations.

Feelings of adequacy. This scale measures an individual's feelings of adequacy or inadequacy in social settings. Adequacy was expected to be a more accurate measure of self concept than more global measures because it emphasizes specific social settings. A shortened 10 -item version, derived from the original 20 -item instrument, was used because it had been shown in previous research to be reliable and valid (Skolnick \& Shaw, 1970). However, several items did not perform as well as expected in the present evaluation so an abbreviated five-item version was used in all data analyses. The resulting scale had an average alpha reliability of .72 in the present study.

Social and personal responsibility. The Social and Personal Responsibility Scale (Conrad \& Hedin, 1981) measures the degree to which youth assume personal and social responsibility in a variety of settings. The scale includes five subscales that assess attitudes on social welfare, duty, personal competence, efficacy, and performance. It is designed for youth ages 12-18 (or 
in grades 6-12). Only the total scale score, and not subscale scores, was used in the present evaluation. The alpha reliability for the total scale was reported by the scale developers to be .83. In the present study, the average alpha reliability was .87 .

Perceived social support. The Scale of Perceived social support was developed by CantyMitchell and Zimet (2000). The scale measures individuals' perceptions of the amount of social support received from non-familial adults. In this instance, the items were focused on the Police and other adults who worked with youth in the Police Working with Youth Programs. The average alpha reliability over two administrations was .89 in this study.

Attitudes toward police. The pre-test and post-test survey administered to youth participants also included 10 items that asked specifically about attitudes toward the police. The items were derived from a community-wide survey originally conducted in New York City to determine residents' attitudes toward local police (Fine et al., 2003).

\section{Results}

\section{Youth Observer Reports of Program Activities}

An important goal of this evaluation was to gain a better understanding of the activities that youth participated in while attending Police Working with Youth Programs. As noted earlier, very few process studies have been conducted that actually document what goes on in youth development programs. Each program was expected to recruit youth who would serve as observers and complete regular reports on what had occurred in their programs. Observer reports were examined for commonalities and consistent themes across programs. The following activities were found to occur regularly in the Police programs that participated in the evaluation.

Planning meetings. All programs (100\%) conducted planning meetings. Meetings were held with youth to discuss goals for the project year. Youth chose what activities they would be involved in and when they would occur. They then helped with organizing specific details of the upcoming events. For instance, youth helped plan future meetings, created "plans of action" to recruit other youth into the program, and helped select fund raising events and field trips.

Training sessions. Most (88\%) of the programs offered training sessions. Training sessions generally included an orientation to the Police Working with Youth programs. The youth also received training (knowledge and skill building) in such areas as: learning how to conduct a meeting, effective communication skills, internet safety, public speaking, building team work, community safety, resources available in their communities, disabilities and diversity issues, drugs and alcohol, social skills, and dealing with stress.

Some of the programs provided specialized training focused on police work and the police profession. One town provided youth with a "crime-scene investigation" experience, where they learned to recognize specifics about their surroundings. Youth learned how to finger print and had the chance to fingerprint their peers. Youth were able to learn about detective work and working with K-9's in law enforcement. They also learned how to perform military drills, marching movements, salutes, and direct traffic.

Field trips. Most (75\%) of the Police Working with Youth programs went on field trips. The field trips tended to fall into two categories: (1) Recreational: Ice skating, sleigh riding, bowling, rafting, hiking, hayrides, golf lessons, restaurants, and movies, and (2) Educational: Pequot 
Museum, Mystic Aquarium, tour of historic Boston, tour of Police Stations and a trip to a youth prison, where youth learned first-hand how individuals their own age live while incarcerated.

Club events. All (100\%) of the programs had special club events held specifically for participants. Many (63\%) of the programs held festivities to celebrate holidays, such as Thanksgiving dinners, Christmas parties, pumpkin decorating, and a Valentine's Day dance. The Police Working with Youth programs sponsored other small celebrations such as a welcome home party for an officer who served in Iraq. Club events also included sports-related organized activities, such as relay races, volleyball games, and laser tag.

Community service activities. Many (63\%) of the Police programs engaged youth in activities within their own communities that were intended to give participants a sense of ownership in their hometowns. These activities included cleaning up playgrounds, developing a teen reading area in the local library, giving input to a landscaping project in the center of town, holding a community picnic, and volunteering at booths in the local fair. Additionally, one town sponsored a late teen-night activity as a drug-free alternative activity for youth.

Meaningful involvement. In $63 \%$ of the programs, youth were provided a sense of ownership and affiliation in their particular "Police Working with Youth" groups. They planned activities, chose official logos, received special t-shirts, and assisted in the fitting and ordering of their own uniforms.

Youth engagement with police. Although a basic goal of the Police Working with Youth programs was to bring youth and police together in meaningful ways, it was noteworthy that many programs (63\%) made a concerted effort to teach youth about police. Youth Participants were introduced to officers, including detectives, chiefs, and captains and provided "question and answer" sessions with police where they could learn about the profession and discuss misconceptions youth have about police. Opportunities to spend recreation time with officers to facilitate more positive relationships between youth and police were established. A primary emphasis in this regard was to teach youth participants new ways to communicate with police. The next section provides additional data on the outcome of these efforts.

\section{Changes in Attitudes toward Police}

An important goal of Police Working with Youth Programs was to enhance young peoples' perceptions about the police. To determine whether or not youth reported significant changes on any of the 10 items, t-tests for related samples were computed for each item individually. The results indicated that youth reported significant changes on four of the 10 items. The findings are summarized in Table 1. 
Table 1

Average Scores on Each Item Pertaining to Youth's Attitudes toward the Police $(\mathrm{N}=68)$

\begin{tabular}{|c|c|c|c|c|}
\hline Police in my community... & Pre-test & Post-test & $\mathrm{t}$ & Sig. \\
\hline respect people like me & 3.18 & 3.36 & 1.99 & .05 \\
\hline are here to help protect people like me & 3.42 & 3.45 & .32 & $\mathrm{n} / \mathrm{s}$ \\
\hline are more willing to threaten someone like me & 3.34 & 3.32 & -.14 & $\mathrm{n} / \mathrm{s}$ \\
\hline $\begin{array}{l}\text { sometimes will allow crimes to happen without } \\
\text { stopping them }\end{array}$ & 3.34 & 3.25 & -.70 & $\mathrm{n} / \mathrm{s}$ \\
\hline do their jobs well & 3.28 & 3.43 & 1.49 & $\mathrm{n} / \mathrm{s}$ \\
\hline enjoy being police officers & 3.18 & 3.42 & 2.34 & .05 \\
\hline unfairly use abusive language with some people & 3.09 & 3.21 & .89 & $\mathrm{n} / \mathrm{s}$ \\
\hline \multicolumn{5}{|l|}{ I... } \\
\hline feel comfortable when I see the police on the streets & 3.10 & 3.39 & 2.26 & .05 \\
\hline $\begin{array}{l}\text { do not really think about the police I see on the } \\
\text { streets }\end{array}$ & 2.79 & 2.50 & -2.36 & .05 \\
\hline $\begin{array}{l}\text { worry that the police I see on the streets will bother } \\
\text { my friends or me }\end{array}$ & 3.22 & 3.16 & -.45 & $\mathrm{n} / \mathrm{s}$ \\
\hline
\end{tabular}

The above results suggest that youth felt more comfortable with, and respected by, the police as a result of their involvement in the Police Working with Youth Programs. Additional outcome results are presented in the next section.

\section{Youth Outcome Results}

This evaluation was designed to assess changes in participants who completed the year-long Police Working with Youth programs in 2005. Indicators of the youth development outcomes described earlier were administered to youth involved in the Police programs at the beginning and end of the project year. Statistical analyses, involving youth between the ages of 12 and 18 , were conducted using repeated measures analysis with pre-test and post-test scores as the within subjects factor. Each outcome measure was examined separately. The repeated measures analyses on each outcome measure were repeated several times with a separate between subjects factor included each time. This was done so that subgroup differences among youth participants could be examined.

Several grouping factors were reduced to fewer categories than were originally present in the data in order to ensure relatively equal subgroup sizes for statistical power purposes. For instance, grade level was reduced to three groups that included: (1) grades 5, 6 and 7; (2) grades 8 and 9; and (3) grades 10,11, and 12. In addition to the issue of equal groups, it was thought that these sub-groupings also represented differing developmental levels among youth. Grade point average was collapsed into three groups: (1) A-average, (2) B- average, and (3) Caverage because $98 \%$ of the sample fell within these three categories. The race/ethnicity categories were also collapsed into two groups: (1) White and (2) African American and Hispanic Latino. Other racial/ethnic subgroups were excluded due to very small numbers. Again, this was done to ensure adequate subgroup sample sizes. Also, preliminary comparisons indicated that African American and Hispanic/ Latino youth did not differ statistically on any of the outcome measures included in the evaluation.

Self-regulatory efficacy. A significant two-way interaction was found between time and ethnic/racial group status $[F(2,57)=9.47 ; p<.001]$. African American and Hispanic/Latino 
youth were significantly more likely to increase their scores on self-regulatory efficacy following completion of the program than were White youth. These results are summarized in Table 2.

\section{Table 2}

Changes in Self-Regulatory Efficacy Scores Following Program Completion for Youth in Different Ethnic/Racial Groups

\begin{tabular}{|l|c|c|c|}
\hline Ethnic/Racial Group & $\mathrm{N}$ & Pre-Test & Post-Test \\
\hline White & 47 & 51.74 & 50.21 \\
\hline $\begin{array}{l}\text { African American \& } \\
\text { Hispanic/Latino }\end{array}$ & 13 & 38.54 & 48.92 \\
\hline
\end{tabular}

Another significant two-way interaction was found between time and grade level $[F(2,64)=$ 7.93; $p<.001]$. Youth in the lower grades were significantly more likely to improve their scores on self-regulatory efficacy following completion of the program than were youth in the higher grades (see Table 3).

Table 3

Changes in Self-Regulatory Efficacy Scores Following Program Completion for Youth in Different Grade Levels

\begin{tabular}{|l|c|c|c|}
\hline Grade Level in School & $\mathrm{N}$ & Pre-Test & Post-Test \\
\hline Grades 5-7 & 15 & 38.40 & 47.47 \\
\hline Grades 8-9 & 26 & 51.96 & 49.73 \\
\hline Grades 10-12 & 26 & 51.11 & 50.81 \\
\hline
\end{tabular}

These results indicate that those most likely to improve their capacity to resist negative peer pressures following completion of the programs were younger (grades 5-7) and from minority (African American or Hispanic/Latino) backgrounds.

Sense of mastery. A significant two-way interaction was found between time and racial/ethnic background $[F(1,53)=4.95 ; p<.05]$. This indicated that African American and Hispanic/Latino youth were more likely to increase their scores on the sense of mastery measure following completion of the program. In contrast, White youth who completed the program remained essentially unchanged on this outcome (see Table 4). However, it should be noted that only 10 youth comprised the Latino/African American group.

Table 4

Changes in Sense of Mastery Scores Following Program Completion for Youth in Different Ethnic/Racial Groups

\begin{tabular}{|l|c|c|c|}
\hline Ethnic/Racial Group & $\mathrm{N}$ & Pre-Test & Post-Test \\
\hline White & 45 & 22.82 & 22.67 \\
\hline $\begin{array}{l}\text { African American \& } \\
\text { Hispanic/Latino }\end{array}$ & 10 & 19.20 & 21.70 \\
\hline
\end{tabular}

Social support from significant non-familial adults. A significant main effect for time $[F(1,58)=$ 2.79; $\mathrm{p}<.05$ ] indicated that all youth, regardless of their gender, grade level, grade point 
average, or ethnic/racial background, reported an increase in their mean scores. Average scores among all youth increased from 16.29 to 17.46 on the social support measure.

Social responsibility. A significant two-way interaction was found between time and average grades in school (GPA) $[F(2,51)=3.49 ; p<.05]$. An inspection of Table 5 indicates that participants who had a B-average in school improved slightly in the sense of social responsibility at the end of the program. However, the biggest change was among participants who reported having a $\mathrm{C}$ - average in school. This group reported the largest decline in their sense of social responsibility following completion of the program.

\section{Table 5}

Changes in Sense of Social Responsibility Scores Following Program Completion for Youth with Different Grade Point Averages

\begin{tabular}{|c|c|c|c|}
\hline $\begin{array}{c}\text { Overall Grade Point } \\
\text { Average in School }\end{array}$ & $\mathrm{N}$ & Pre-Test & Post-Test \\
\hline A & 20 & 69.95 & 69.15 \\
\hline B & 24 & 63.33 & 64.79 \\
\hline C & 10 & 64.90 & 59.30 \\
\hline
\end{tabular}

Characteristics of youth in lower grades or from minority ethnic/racial backgrounds. The findings that some groups of youth reported more positive changed than others prompted some additional questions. Specifically, what other characteristics might describe those youth in lower grades or from minority ethnic/racial backgrounds who had reported the most change on several outcome measures? Chi square analyses were conducted to asses how youth in lower grades might differ from youth in higher grades and how minority youth might differ from White youth.

Youth in lower grades were significantly more likely to:

(1) report being African American or Hispanic rather than White $\left[X^{2}(2)=23.24 ; p<.001\right]$,

(2) live in an alternative family arrangement such as with mother-only or with father and step-mother rather than with two biological parents $\left[X^{2},(10)=17.98 ; p<.05\right]$, and

(3) have participated in the program for a longer period of time (1 to 2 years as opposed to 3 months) $\left[X^{2}(10)=18.63 ; \mathrm{p}<.05\right]$.

African American or Hispanic/Latino youth were significantly more likely to:

(1) be in the lower grades (5-7 rather than 8-9 or $10-12)\left[X^{2}(2)=24.79 ; p<.001\right]$, or

(2) have spent more time in the program than White youth ( 1 to 2 years versus 3 months) $\left[X^{2}(4)=19.60 ; p<.001\right]$.

It appears that the youth who were most likely to benefit from the Police programs shared several additional attributes in common. In addition to being younger (in lower grades at school) and having minority ethnic/racial backgrounds, they were also more likely to have spent more time in the program and lived in non-traditional family arrangements.

\section{Core Program Components and Youth Outcomes}

Regression analysis was utilized to test which program components from among the set of components identified earlier were significantly associated with youth outcomes. Program components were coded as $1=$ present or $0=$ not present in each police program. In order to 
analyze these data, backward elimination was selected because we were interested in identifying the program components that accounted for the largest percentage of the variance in each of the outcome indicators after controlling for all other program components. Only the five components that had some variance (training, field trips, community service, meaningful involvement and youth engagement) were included. Planning meetings and club events were excluded because they were present in $100 \%$ of the programs. Pre-test and post-test change scores for each of the five outcomes were examined separately as the dependent variables.

The results indicated that meaningful involvement was a significant predictor of improvements in participants' levels of self-adequacy in social situations $F(1,49)=4.18, p<.05$, accounting for $8 \%$ of the variance (Standardized beta $=.28 ; t=2.05 ; p<.05$ ). Regression results for the participants' changes in self-regulatory efficacy (ability to resist peer pressures) were similar. Meaningful Involvement was the only noteworthy predictor $F(1,50)=2.90, p<.10$, accounting for $6 \%$ of the variance (Standardized beta $=.23 ; t=1.70 ; p<.10$ ). However, given the imprecise measurement of the process measures of core program components in the study, these results should be considered only exploratory.

\section{Conclusions}

Several conclusions can be drawn from this evaluation of Police Working with Youth programs. The observational data provided by youth participant observers indicated that all Police Working with Youth Programs offered youth opportunities to engage in a variety of stimulating and interesting activities. These included structured planning meetings, club events, training sessions, and a variety of field trips. Many programs (63\%) also provided opportunities for youth to become meaningfully involved in their programs through active engagement in program planning and decision-making. Stimulating activities and meaningful involvement are two of the core components proposed to be essential for successful youth development programs (Catalano et al., 2002; Eccles \& Gootman, 2002; Eccles et al., 2003; O’Donoghue et al., 2002; Roth et al., 1998; Walker et al., 2005).

Although previous formulations have included active participation in one's community as part of the definition of meaningful youth involvement (e.g., O'Donoghue et al., 2002; Tolman \& Pittman, 2001), a distinction was made in this study between meaningful involvement within the program and meaningful involvement in the broader community through community service activities. This distinction between program and community involvement appears to have been supported by the data. Only $41 \%(n=55)$ of youth participated in programs that offered both community service and meaningful involvement opportunities. The rest were in programs that offered only one of the two components $(23 \%, \mathrm{n}=30)$ or neither component $(36 \%, \mathrm{n}=48),\left[X^{2}\right.$ $(1)=41.18 ; p<.001]$. Future research efforts might also wish to consider meaningful involvement within youth development programs as distinct from meaningful involvement in the broader community.

The outcome evaluation portion of the study demonstrated several important results. The entire sample of youth participants reported significant increases in the amount of social support they received from significant, non-familial adults. This is an important finding because supportive relationships with staff and other non-familial adults is another frequently identified characteristic of effective youth programs (Anderson-Butcher et al., 2004; Catalano et al., 2002; Eccles \& Gootman, 2002; Loder \& Hirsch, 2003; Noam \& Fiore, 2004; Rhodes, 2004; Roth et al., 1998). 
Subgroups of youth, most notably minority youth and younger participants in lower grade levels, reported additional positive changes. Both of these subgroups reported positive changes in self-regulatory efficacy. Additionally, minority youth reported positive changes in their sense of mastery over stressful life situations. The capacity to resist negative peer pressures and to feel confident in managing difficult life situations are the types of personal coping resources and protective factors that have been found to promote healthy adolescent development (Benson, 2002; Eccles \& Gootman, 2002; Larson, 2000; McLaughlin, 2000).

Some results were notably different from the results obtained in an earlier evaluation of Police Working with Youth Programs that was completed in 2004. In the earlier evaluation, neither minority youth nor younger youth reported significant changes following completion of the programs compared to other youth. It is not clear what might account for this difference. It might be that these programs made concentrated efforts to tailor their programs to the needs of different subgroups. Alternatively, the findings might reflect differences in the samples of youth included in each evaluation. For instance, only four of the communities included in the current evaluation participated in the earlier one. In any event, it is important to highlight these differences because they suggest that different police programs are able to work successfully with different subgroups of youth.

The data also suggested that one subgroup of youth might not be responding well to the Police programs. Youth who reported doing more poorly in school, as indicated by lower grade point averages, showed decreased scores on the social responsibility outcome. That is, youth participants with lower grades in school showed a decline in their commitment to, and actions toward, helping the community and fostering the well-being of others following completion of the programs. Although the meaning of this single finding remains unclear, it suggests that programs may want to give some additional attention to assessing the needs of those individuals who enter the programs with less academic success.

The final set of analyses attempted to link the process and outcome data by examining the associations between core program components and participants' reported changes following completion of the Police programs. As was noted earlier, little evidence is available from previous research to indicate what program components or combination of components within effective youth programs are responsible for positive outcomes (Eccles, 2005; Eccles \& Gootman, 2002; Kahne et al., 2001; Lopez \& McKnight, 2002; Scott-Little, Hamann, \& Jurs, 2002). Meaningful involvement was the one core program component found to predict youth improvements in self-adequacy in social situations and self-regulatory efficacy (ability to resist peer pressures). This finding is consistent with the youth leadership literature that views young peoples' meaningful involvement in all aspects of program planning and implementation as an essential goal. Active participation in program planning, an authentic voice in decision-making, a sense of group membership, opportunities to influence the group's direction and accomplishing group-defined goal are hallmarks of youth leadership development programs (Boyd, 2001; MacNeil, 2006; Zeldin \& Camino, 1999). However, given the imprecise nature of the process measures used to assess core program components in this study, these results should be considered exploratory and yet a fruitful area for further investigation.

Based upon the survey and observational data, it appears that the Police Working with Youth programs involved in this evaluation have incorporated many of the core components identified in prior research to be present in high quality youth programs. Feeling supported by staff, a sense of meaningful involvement, and engagement in stimulating and challenging activities are all important elements of effective youth programs. 
As in any evaluation, the findings also raise additional questions. We still do not know what motivates youth to become involved in Police Working with Youth programs in the first place. Nor do we know what kinds of individuals are most likely to enroll, participate regularly, and complete the program. Furthermore, are there other characteristics, in addition to age and ethnicity that might differentiate those who do well in the program from those who do less well?

A more extensive process evaluation would be useful in addressing the questions posed above, such as who participates and why. Furthermore, additional efforts directed toward collecting attendance data on individual participants could address the question of whether regular (in contrast to infrequent) attendance improves youth outcomes. Finally, future efforts need to be directed toward developing research designs that allow for more compelling conclusions about the relationships between program implementation processes (program components) and youth outcomes.

\section{References}

Anderson-Butcher, D.A., Cash, S.J., Saltzburg, S., Midle, T., \& Pace, D. (2004). Institutions of youth development: The significance of supportive staff-youth relationships. Journal of Human Behavior in the Social Environment, 9(1/2), 83-99.

Anderson, S.A., Sabatelli, R.M., \& Trachtenberg, J. (2007). Community police and youth programs as a context for positive youth development. Police Quarterly.

Bandura, A. (in press). Guide for constructing self-efficacy scales. In Pajares, F., \& Urdan, T. (Eds.). Adolescence and education, Vol. 4: Self-efficacy beliefs of adolescents. Greenwich, CT: Information Age Publishing.

Bandura, A. (2001). Guide for constructing self-efficacy scales. Stanford University. (Unpublished).

Bandura, A. (1997). Self-efficacy: The exercise of control. New York: Freeman.

Benson, P.L. (2002, Fall). Adolescent development in social and community context: A program of research. New Directions for Youth Development, 95, 123-147.

Bowlby, J. (1988). A secure base: Clinical applications of attachment theory. London: Routledge.

Boyd, B.L. (2001). Bringing leadership experiences to inner-city youth [Electronic Version]. Journal of Extension, 39, 1-5.

Canty-Mitchell, J., \& Zimet, G.D. (2000). Psychometric properties of the multidimensional scale of perceived social support in urban adolescents. American Journal of Community Psychology, $28(3), 391-403$. 
Catalano, R.F., Berglund, M.L., Ryan, J., Lonczak, H.S., \& Hawkins, D. (2002). Positive youth development in the United States: Research findings on evaluations of positive youth development programs. Prevention and Treatment, 5 (15), 1-106.

Connell, J., Gambone, M.A., \& Smith, T. (2000). Youth Development: Issues, challenges and directions. Philadelphia, PA: Public/Private Ventures.

Conrad, D. \& Hedin, D. (1981). Instruments and Scoring Guide of the Experimental Education Evaluation Project. Center for youth development and research. St. Paul, MN: University of Minnesota.

Dehar, M., Casswell, S., \& Duignan, P. (1993). Formative and process evaluation of health promotion and disease prevention programs. Evaluation Review, 17, 204-220.

Durlak, J.A., \& Wells, A.M. (1997). Primary prevention mental health programs for children and adolescents. American Journal of Community Psychology, 25, 115-152.

Durlak, J.A., \& Wells, A.M. (1998). Evaluation of indicated preventive intervention (secondary prevention) mental health programs for children and adolescents. American Journal of Community Psychology, 26, 775-802.

Eccles, J. (2005). The present and future of research on activity settings as developmental contexts (pp. 353-371). In J.L. Mahoney, R.W. Larson, \& J.S. Eccles (Eds.), Organized activities as contexts of development. Majwah. NJ: Lawrence Erlbaum Associates.

Eccles, J., \& Gootman, J.A. (2002). Community programs to promote youth development. Washington, DC: National Academy Press.

Eccles, J., Stone, M., \& Hunt, J. (2003). Extracurricular activities and adolescent development. Journal of Social Issues, 59, 865-889.

Erikson, E.E. (1968). Identity: Youth and crisis. New York: Norton.

Fine, M., Freudenberg, N., Payne, Y., Perkins, T., Smith, K., \& Wanzer, K. (2003). "Anything Can Happen With Police Around": Urban Youth Evaluate Strategies of Surveillance in Public Places. Journal of Social Issues, 59, 141- 158.

Gambone, M.A., \& Arbreton, A.J. (1997). Safe havens: The contributions of youth organizations to healthy adolescent development. Philadelphia: Public/Private Ventures.

Gambone, M.A., Cao Yu, H., Lewis-Charp, H., Sipe, C.L., \& Lacoe, J. (2004). A comparative analysis of community youth development strategies. College Park, MD: Center for Information and Research on Civic Learning and Engagement, University of Maryland School of Public Policy.

Greene, J.R. (2000). Community policing in America: Changing the nature, structure, and function of police. In J. Homey (Ed.), Criminal Justice 2000: Policies, Processes, and Decisions of the Criminal Justice System (pp 299-370). Washington, D.C.: U.S. Department of Justice, Office of Justice Programs. 
Halpern, R., Barker, G., \& Mollard, W. (2000). Youth programs as alternative spaces to be: A study of neighborhood youth programs in Chicago's West Town. Youth \& Society, 31, 469-506.

Hamilton, M.A., \& Hamilton, S.F. (2004). Designing work and service for learning. In S.F. Hamilton \& M.A. Hamilton (Eds.), The youth development handbook: Coming of age in American communities. Thousand Oaks, CA: Sage.

Hirsch, B.J. (2005). A place to call home. Washington, DC: American Psychological Association Press.

Kahne, J., Nagaoka, J., Brown, A., O'Brien, J., Quinn, T., \& Thiede, K. (2001). Assessing afterschool programs as contexts for youth development. Youth \& Society, 32 (4), 421-446.

Larson, R.W. (2000). Toward a psychology of positive youth development. American Psychologist, 55, 170-183.

Loder, T.L., \& Hirsch, B.J. (2003). Inner-city youth development organizations: The salience of peer ties among early adolescent girls. Applied Developmental Science, 7, 1, 2-12.

Lopez, S., \& McKnight, C.G. (2002). Moving in a positive direction: Toward increasing the utility of positive youth development efforts. Prevention \& Treatment, 5, number 7.

MacNeil, C. (2006). Bridging generations: Applying adult leadership theories to youth leadership development. New Directions for Youth Development, 109, 27-43.

McLaughlin, M. (2000). Community counts. How youth organizations matter for youth development. Washington, DC: Public Education Network.

McLaughlin, M.W. (1987). Implementation realities and evaluation design. Evaluation Studies Review Annual, 12, 73-97.

McLaughlin, M., Irby, M., \& Langman, J. (2001). Urban sanctuaries: Neighborhood organizations in the lives and futures of inner-city youth ( ${ }^{\text {nd }}$ ed. $)$, San Francisco, CA: Jossey-Bass.

Miller, J.W., Coombs, W.T., \& Fuqua, D.R. (1999). Examination of Psychometric Properties of Bandura's Multidimensional Scales of Perceived Self-Efficacy. Measurement and Evaluation in Counseling and Development, 31 (4), 186-196.

Noam, G.G., \& Fiore, N. (2004, Fall). Relationships across multiple settings: An overview. New Directions for Youth Development, 103, 9-16.

O'Donoghue, J.L., Kirshner, B., \& McLaughlin, M. (2002, Winter). Introduction: Moving youth participation forward. New Directions for Youth Development, 96, 15-26.

Pearlin, L., \& Schooler, C. (1978). The structure of coping. Journal of Health and Social Behavior, 19, 2-21.

Posner, J.K., \& Vandell, D. (1994). Low-income children's after-school care: Are there beneficial effects of after-school programs? Child Development, 65, 440-456. 
Rabois, D., \& Haaga, D. (2003). Facilitating police-minority youth attitude change: The effects of cooperation within a competitive context and exposure to typical exemplars. Journal of Community Psychology, 30, 189-195.

Rhodes, J. (2002). Stand by me. The risks and rewards of mentoring today's youth. Cambridge, MA: Harvard University Press.

Rhodes, J.E. (2004, Spring). The critical ingredient: Caring youth-staff relationships in afterschool settings. New Directions for Youth Development, 101, 145-161.

Rohner, R.P., \& Britner, P.A. (2002). Worldwide mental health correlates of parental acceptance-rejection: Review of cross-cultural and intra cultural evidence. The Journal of Comparative Social Science, 36, 15-47.

Roth, J., Ryan, J., Gaffigan, S., Koper, C., Moore, M., Roehl, J., et al. (2000). National evaluation of the COPS Program: Title I of the 1994 Crime Act. Washington, D.C.: U.S. Department of Justice, National Institute of Justice, NCJ 183643.

Roth, J.L., \& Brooks-Gunn, J. (2003). Youth development programs: Risks, prevention and policy. Journal of Adolescent Health, 32, 170-182.

Roth, J., Brooks-Gunn, J., Murray, L., \& Foster, W. (1998). Promoting healthy adolescents: A synthesis of youth development program evaluations. Journal of Research on Adolescence, 8 , 423-459.

Sabatelli, R.M., Anderson, S.A., \& Lamotte, V.A. (2005). Assessing outcomes in child and youth programs: A practical handbook, revised edition. Hartford, CT: State of Connecticut, Office of Policy and Management. Available at http://www.opm.state.ct.us/pdpd1/grants/jiac/JJACPublications.htm\#Police\%20Policies

Scott-Little, C., Hamann, M.S., \& Jurs, S.G. (2002). Evaluations of after-school programs: A meta-evaluation of methodologies and narrative synthesis of findings. American Journal of Evaluation, 23, 387-419.

Skolnick, P., \& Shaw, J. (1970). Brief note on the reliability of the Janis and Field "Feelings of Inadequacy" scale. Psychological Reports, 27, 732-734.

Thurman, Q.C., Giacomazzi, A., \& Bogen, P. (1993). Research note: Cops, kids, and community policing: An assessment of a community policing demonstration project. Crime \& Delinquency, 39, 554-564.

Tolman, J., \& Pittman, K. (2001). Youth acts, community impacts: Stories of youth engagement with real results. Takoma Park. MD: Forum for Youth Investment, International Youth Foundation.

Vandell, D.L., Shumow, L., \& Posner, J. (2005). After-school programs for low-income children: Differences in program quality (pp. 437-456). In J.L. Mahoney, R.W. Larson, \& J.S. Eccles (Eds.), Organized activities as contexts of development. Majwah. NJ: Lawrence Erlbaum Associates. 
Walker, J., Marczak, M., Blyth, D., \& Borden, L. (2005). Designing youth development programs: Toward a theory of developmental intentionality (pp. 399-418). In J.L. Mahoney, R.W. Larson, \& J.S. Eccles (Eds.), Organized activities as contexts of development. Majwah. NJ: Lawrence Erlbaum Associates.

Wholey, J.S., Hatry, H.P., \& Newcomer, K.E. (1994). Handbook of practical program evaluation. San Francisco: Jossey-Bass.

Yohalem, N., Pittman, K., \& Wilson-Ahlstrom, A. (2004, Spring). Getting inside the "black box" to measure program quality. The Evaluation Exchange, 10, 6-7.

Zeldin, S., \& Camino, L. (1999). Youth leadership: Linking research and program theory to exemplary practice. New Designs for Youth Development, 15 (1), 10-15.

(C) Copyright of Journal of Youth Development $~$ Bridging Research and Practice. Content may not be copied or emailed to multiple sites or posted to a listserv without copyright holder's express written permission. Contact Editor at: patricia.dawson@oregonstate.edu for details. However, users may print, download or email articles for individual use.

ISSN 2325-4009 (Print); ISSN 2325-4017 (Online) 